\title{
MÁRIO DE ANDRADE E HENRIQUETA LISBOA
}

\section{Alaíde Lisboa de Oliveira}

Depoimento apresentado pela autora no Centro Cultural de São Paulo, em 27/08/92, por ocasião das comemorações dos 70 anos da "Semana de Arte Moderna" e a convite da Secretaria Municipal de Cultura de São Paulo e do Instituto de Estudos Brasileiros da USP. Da mesa-redonda também participaram Antonio Candido e Décio de Almeida Prado.

Muito se tem cogitado sobre os sentimentos que caracterizam as cartas de Mário de Andrade a Henriqueta Lisboa. Essas cogitações suscitam a análise da amizade entre homem e mulher, e ainda mais entre homem e mulher intelectuais. Já se disse que nesse caso pode haver amor, pode haver hostilidade e pode haver culto mas se exclui amizade. Faço minha opção por culto, em que a afetividade complemente, complete, envolva o culto.

É comum dizer-se que amamos os pais, os irmãos, os filhos e até amamos o povo, mas se a amiga diz que ama o amigo, a conotação de amor se modifi- 
ca; por quê? Realmente a amizade entre homem e mulher se reveste de muita sutileza, muito requinte e se torna difícil traduzir a amor-amigo.

E como será esse amor-amizade entre dois intelectuais?

Como serão as nuances desse culto-afetivo à distância? As dedicatórias ao lado das cartas denotam esse bem-querer - e na associação coração e espirito.

Como será lido o livro de autoria do amigo pela amiga ou a amiga pelo amigo? Talvez como se estivesse ouvindo uma sinfonia: os sons absorvem as expressões, a melodia das frases se associa às idéias, o espínito penetra na profundidade de cada pensamento transposto em letra de forma, e ele ou ela fica a imaginar aquela mão, aqueles dedos, aquele cérebro no momento da criação literária ou científica, e a prever o momento de reencontro pessoal para nova comunicação; até a voz, aí relembrada, como que mantém o timbre, a sonoridade real daquele momento em que a fala foi envolvida.

Das dissertações nos livros ou das exposiçōes orais fica a lembrança viva da fala, fisicamente, intelectualmente, a toda sensibilidade, num transcender da matéria para o espírito, do espírito para o espírito, do coração para o coração, do cotidiano para o raro.

$\mathrm{E}$ nos reencontros, de amigo e amiga, nas páginas alheias, de poetas, romancistas, ensaístas, cada um a imaginar o que pensaria o outro naquela leitura; como o outro resolveria suas dúvidas; cada um a querer adivinhar as impressões que o outro teria, as interpretações, os julgamentos críticos. E o mundo das cogitações de um será o mundo das cogitações dos dois.

Em que se diferenciaria a amizade do amor?

A amizade seria doação? O amor seria exigência?

$\mathrm{Na}$ troca de cartas entre amigo e amiga intelectuais, as cartas são vividas por quem as escreve e por quem as lê. A amizade conduz o espírito e as mãos escrevem e conduz a alma e os olhos que lêem. E as sutilezas enternecidas, os disfarces afeti- vos se envolvem nas manifestações intelectuais e se fundem em plenitude. É o ir e vir da inteligência para o coração, do coração para a inteligência. É a absorção de belezas do espírito, um devaneio das áreas da cultura. São realidades, pequenas ou grandes, transpostas para o nível indefinido do saber.

Cartas envoltas em belezas reformuladas pela inteligência, irmanadas na sensibilidade. Nas trocas de cartas eles talvez nem sabiam que se amavam, mas sabem que se admiram, que se respeitam, que confiam, um no outro.

As cartas de amiga de Henriqueta aguardam a liberação prevista pelo próprio Mário quando a toda sua correspondência: "50 anos depois de sua morte", faltam poucos anos, essas cartas podem ser pressentidas, adivinhadas, aqui e ali, nas expressões de Mário.

Em Mário a confiança na expansão de sua vida interior, a revelação de sentimentos, angústias, alegrias, enternecimentos. As hesitações confessionais, as certezas de sentimentos, a fuga ao sentimentalismo. Comunicar-se, ter um ouvinte querido, era profundamente necessário; as auto-análises tinham de ser divididas, ao mesmo tempo em que sua alma transbordava, encolhia-se, não queria ultrapassar medidas que o próprio eu determinasse. Mário sabia até liberar o seu exigir, sem ser contraditório; amava sobretudo a verdade, a sinceridade e, mais importante, confiava na amiga.

Nestas cartas vamos ver ainda que as confissões de Mário são mais espontâneas, mais humanas, mesmo nas referências a problemas intelectuais. $\mathrm{O}$ modo de pensar e o de sentir se integram nos comentários de idéias. As belezas de sua alma se revelam no que ele diz e no como diz. A liberdade lingüística traduz uma oposição à violência das margens, das normas, mas sem agressão, numa atitude de busca de expressão natural de pensamento e sentimento.

A espiritualidade transcende o cotidiano, e não importa a distância do convívio pessoal: "Poucas vezes te vi, sempre te amei". 
E vamos lembrar Fernando Pessoa:

Temos todos que vivemos

uma vida que é vivida

e outra vida que é pensada.

O prefácio do Padre Lauro Palu, todo sabedoria, ilumina os caminhos da interpretação das belas cartas de Mário a Henriqueta.

\section{NO MODERNISMO}

As reações modernistas de Mário de Andrade, em relação à língua, aos problemas linguísticos em si mesmos, e em relação às técnicas e processos renovadores, na Poesia, na Arte são muito mais sólidas, mais equilibradas, mais lúcidas do que pensavam os adversários, os opositores da época (e que fizeram Mário sofrer).

Basta ler pequenos trechos das cartas aos amigos, para uma melhor compreensão das intençōes, das perspectivas de Mário; quantas vezes num simples comentário de algum trabalho do amigo ele revela, com segurança suas idéias. Na própria forma expressiva de Mário, na linguagem, no emprego de recursos originais, as novidades aparecem como acréscimo, e nunca com espírito destrutivo. $\mathrm{O}$ vocabulário e a estrutura de frases usadas nos trabalhos dos amigos sofrem observações de ponderadas convicções de Mário.

Vamos ver algumas observações suas, sobre objetivos e planos:

Pretende-se "língua brasileira que corresponda ao nosso caráter, realidade, função" ${ }^{1}$

A gente não deve se esquecer que não estamos fazendo uma fotografia do falar oral e sim uma organização literária, fotografála não é dar uma solução que tenha viabilidade literária, e nem siquer prática. ${ }^{2}$

Cauteloso continua "o trabalho que nós temos é imenso, não basta intuição, tem que estudar estu-

1. ANDRADE, p. 53.

2. Ibidem, p. 53 - 54. dar refletir refletir e com cuidado e com paciência fazer tudo em terreno novo"3.

Alguma coisa há de ficar (e ficou muito).

Não tem nada como a gente se respeitar, a si mesmo. Isso não é vaidade, é dever é um trabalho imenso em que agora você terá de botar a vida inteirinha se quiser mesmo alguminha coisa.

A solução de você tem isso de valiosíssimo, por mais que você empregue termos e modismos caboclos você conserva uma suntuosidade artística na dicção que é eminentemente literária e não oral ... fala oral brasileira já a gente possui e não carece dela, a independência verdadeira está justamente em construir uma linguagem literária peculiarmente da gente baseada na fala oral e distinta". E continua: "a técnica processual tem uma importância extraordinária e isso de naturalidade, sinceridade e ignorância, tudo são fadigas momentâneas de cérebros moços ${ }^{4}$.

Sobre criação poética, Mário adverte ${ }^{5}$ cuidadosamente, sabiamente: "O perigo é que em vez de você se deixar levar pelo estado lírico, você se preocupou mais com o processo com que se realiza o fato exterior, em vez de observar o seu estado psicológico e por ele descrever o fato exterior. Em vez de processos técnicos, síntese, onomatopéias, superposição simultânea de palavras. combinações orais, em vez dos processos técnicos serem um meio para você realizar sua sensação e emoção - fim da poesia, destino dela - foi uma certa sensação que você escolheu para poder empregar e mostrar certos processos técnicos modernos. Assim para você (ao menos nestes dois poemas) a sensação é um meio, o processo técnico em fim". "No fundo a poesia é uma só e continua a ser tradicional, seguindo a linha comprida que do homem da caverna vem até nós."

3. Ibidem, p. 74.

4. ANDRADE, p. 90.

5. Ibidem, p. 39. 
Essas advertências demonstram a alta compreensão do que seja realmente poesia. E costumo dizer que alguns poetas modernos chegaram a entender que a poesia modema se caracterizava apenas pela mudança de linhas da mensagem. Alguns não percebem as nuanças, o requinte, a graça, a beleza de uma forma chamada livre, mas bem trabalhada, às vezes até a partir de inspiração de uma forma clássica.

Como Mário, várias vezes, demonstrou nas cartas que sofreu com as críticas injustas, achei por bem reunir ponderações, princípios, idéias, afirmações pessoais do Autor, que se constituem em bela defesa em relação a certas incompreensões daqueles momentos primeiros de renovação literária.

Em cartas a Drummond6 Mário afirmava "eu não ataco nem nego a erudição, a civilização, ao contrário, respeito-as" e adiante" "Trata-se de uma estilização culta da linguagem popular, da roça ou da cidade, do passado ou do presente" e, ainda "falo em criar uma linguagem culta brasileira".

\section{LEMBRANÇA DA PRESENÇA DE MÁRIO}

Mário de Andrade, em visita a Henriqueta Lisboa, em Belo Horizonte, teria dito à Amiga que apreciava muito a comida mineira, a couve bem verde, o tutu de feijão, as costelinhas de porco, etc... Tinha eu nesta época uma cozinheira especial e Henriqueta sugeriu um almoço lá em casa. Ao meio dia chegou Mário, tão simpático, muito elegante, de terno marrom, gravata bonita ... Convidamos também, para o almoço, a Profa. Helena Antipoff, aquela mulher extraordinária de pensamento e ação; pessoas geniais, Mário, Helena, Henriqueta se encontravam na casa de Alaíde e Lourenço. E o almoço começou, ao meio dia e meio; os quatro filhos pequenos do casal, sentados, no final da mesa, com olhos arregalados, almoçaram e se retiraram, para expandir energias.

O grupo continuou na mesa até 17 horas, elevadas e belas trocas de idéias centralizadas naquele "Gi-

6. ANDRADE, 1982. p. 24. gante". Quando todos deixaram a mesa, já na sala de visitas, Helena Antipoff que o chamaria de "Gigante" em carta a mim dirigida, exclamou: "Fui feliz durante todas essas horas, muito feliz mesmo", ela que também sabia levar felicidade aos outros.

De volta a São Paulo, poucos meses depois falecia o nosso grande Mário, sociável, encantador, além de tantas riquezas de espírito e coração.

\section{DEPOIMENTO}

José Lourenço de Oliveira conta ${ }^{7}$ que em 1924 chegava a São João Del Rei para exercer o ofício de professor e foi.surpreendido com a presença na cidade de uma caravana de São Paulo que vinha à cidade para assistir a uma Semana Santa. Ao ler o registro de hóspedes do Hotel Macedo transcreveu literalmente a página correspondente ao dia 16 de abril de 1924 .

Eis o curioso registro:

"D. Olivia Guedes Penteado, solt.; photographer, anglaise, Londom.

D. Társia do Amaral; solt.; dentista, americana, Chicago.

Dr. Réné Thiollier, casado; pianista, russo, Rio.

Blaise Cendars, solteiro; violinista, allemand, Berlin.

MÁRIO DE ANDRADE, SOLTEIRO, FAZENDEIRO, NEGRO, BAHIA.

Oswald de Andrade Filho, solt.; escrittore, suíço, Berne.

Oswald de Andrade, viúvo; escolar, holandês, Rotterdam."

A maluquice informativa da resenha, não sei se era obra de um só ou então produto cooperativo. Mas era a mesma letra em que se lavrara.

Seria uma reação irônica de protesto contra a burocracia, o formalismo, o controle tradicional?

E Lourenço comenta mais tarde:

Faz vinte anos que vi o nome de Mário de Andrade num registro de hotel. Este nome cresceu e humanizou-se, até se identificar

7. OLIVEIRA. Ao correr do tempo, p. 77. 
100 ANOS DE MÁRIO

admiravelmente com o homem que depois conheci em Belo Horizonte, na casa de Henriqueta Lisboa. Pude vê-lo, então, de portas a dentro, como diria Frei Luís de Sousa. Era um MÁRIO maior do que o MÁRIO dos livros que li. Um MÁRIO bom, cordial, humano, muito humano.

Relendo-lhe a obra, agora, desde os desvarios da Paulicéia, 1922, até os Aspectos, 1943 , pude ir sentindo, com amor, este homem de minhas predileções.

Mesmo do ponto de vista gramatiqueiro, fui vendo como progrediu para uma linguagem cada vez mais canônica.

O que vale, nele, está para além do escândalo do professor de gramática, e vive, palpitando sob os solecismos propositados, na inspiração, na cultura, na compreensão, na brasilidade, na fraternidade.

Será de um precursor o seu linguajar? Passará ele à consagração de clássico brasileiro?

Quem poderá prenunciar os caminhos da língua e os termos das tendências? (1945)

\section{VISITA A MARIANA}

Para lembrar a integração de Mário de Andrade com Minas e os mineiros trago também um depoimento de Fernando Correia Dias, publicado em Barroco I da série dirigida por Affonso Ávila.

Fernando conta:

Em 1919, Mário de Andrade vai a Mariana. Está visitando as velhas cidades. $E$ mantém contato com Alphonsus, que já tanto admirava. No seu refúgio, o extraordinário simbolista recebe aquele que seria, alguns anos depois, a presença revolucionária mais eminente nas letras brasileiras.

A visita recebida causou-lhe profunda impressão. Mário, assinando M. Morais de Andrade publicaria no ano seguinte na $R e$ - vista do Brasil um artigo intitulado Arte Religiosa no Brasil, no qual descreve a viagem e fala com entusiasmo no Aleijadinho (1920). Alguns anos mais tarde o escritor paulista produzirá sua magistral análise da figura de Antônio Francisco Lisboa, num texto que se tornou clássico. Começava pois a reavaliação crítica da arte colonial mineira.

Essas lembranças mostram a bela associação do movimento renovador com a arte tradicional.

\section{PALAVRAS FINAIS}

Mário de Andrade realmente se revela um gênio tanto através do que escreve, em prosa ou em poesia, como através de suas atividades.

Nas cartas suas idéias se multiplicam, com lúcidas cogitações, análises sobre a criatura humana desde a superfície até o profundo do ser.

E como sabia amar a vida, a humanidade, os amigos. Sua força sensivel se confunde com o alto nível de sua inteligência. Humano, profundamente humano.

Tão grande e em vaidade, estimulava os poetas generosamente.

Sabia valorizar as artes nas suas várias manifestações de escolas e de épocas. Amava São Paulo. Amava também Minas Gerais e era por ela muito amado; assim estou feliz representando aqui o amor de Minas nesta homenagem.

\section{REFERÊNCIAS BIBLIOGRÁFICAS}

1. ANDRADE, Mário de. Cartas a Pedro Nava. Rio de Janeiro: Nova Fronteira, 1982.

2. A lição do amigo; cartas de Mário de Andrade a Carlos Drummond de Andrade. Rio de Janeiro: José Olympio, 1982. 